\title{
AMSR-E Snow: Can Snowfall Help Improve SWE Estimates?
}

\author{
RyAN GONZALEZ AND CHRISTIAN D. KUMMEROW \\ Department of Atmospheric Science, Colorado State University, Fort Collins, Colorado
}

(Manuscript received 9 March 2020, in final form 27 August 2020)

\begin{abstract}
Snowfall and snowpack are tightly coupled within the snow water cycle and careful monitoring is crucial to better understand snow's role in Earth's water and energy cycles. Current and future estimates of the total amount of seasonal snow on the ground are limited by the variability in the initial snowfall and uncertainties in in situ and remote sensing observations. In this study, passive microwave remote sensing estimates of snowfall and snow water equivalent (SWE) from the Advanced Microwave Scanning Radiometer (AMSR-E) instrument are used to assess the consistency in the snow products. A snow evolution model, SnowModel, is employed to simulate snow processes that occur between the initial snowfall and subsequent SWE. AMSR-E is found to have significant discrepancies in both snowfall and SWE compared to MERRA-2 reanalysis and the Canadian Meteorological Centre (CMC) snow product. It is shown that AMSR-E snowfall is currently not a useful metric to estimate SWE without applying large corrections throughout the winter season. Regions of consistency in the AMSR-E snow products occur for reasons that pertain to underestimation in both snowfall and SWE. In addition to snow consistency, microwave brightness temperatures (TBs) are analyzed in response to the snowpack and snowfall physical properties. These experiments indicate significant sensitivity to regime-dependent scattering characteristics that must be accounted for to accurately estimate global snow properties and provide better physical consistency in the snow products from remote sensing platforms.
\end{abstract}

KEYWORDS: Snow; Snowfall; Snowpack; Microwave observations; Remote sensing

\section{Introduction}

Snowfall and snowpack are crucial components of the global water cycle that have direct impacts on both humans and ecosystems. While it is estimated that about one sixth of the world's population depends on snowmelt for their freshwater needs (Barnett et al. 2005), multiple studies have shown that a majority of seasonal snow regions experienced declines in snowpack magnitude, extent, and season length among others parameters due to a warming climate (Mote et al. 2005; Liston and Hiemstra 2011; Pederson et al. 2011; Kunkel et al. 2016; Zeng et al. 2018). To better prepare for future changes, it is critically important from a water resource perspective to carefully monitor changes in these snowpacks.

Levizzani et al. (2011) estimated roughly $40 \%-80 \%$ of precipitation at latitudes poleward of $40^{\circ} \mathrm{N}$ falls as snow. Snowpack evolution studies depend critically on the initial snowfall magnitude, which has been shown to vary in reanalyses and observation-driven precipitation products (Bosilovich et al. 2008; Hancock et al. 2014; Mudryk et al. 2015; Broxton et al. 2016). Therefore, snowfall and snow water equivalent (SWE) are tightly coupled within the snow water cycle. Incorrect snowfall will lead to errors in the resulting SWE, and incorrect representations of SWE within models will impact soil moisture and surface fluxes that feedback to atmospheric circulations (Syed et al. 2008). Accurate global monitoring of snowfall and SWE is central to developing a better representation of snow's role in the climate and hydrology as well as its expected future changes.

Large uncertainties remain in accurately measuring global snowfall and SWE due to the range of scales on which snow

Corresponding author: Ryan Gonzalez,ryan.gonzalez@colostate.edu processes operate. For snowfall, there are difficult problems related both to the distribution as well as measurement technologies. Orographic forcing plays a key role in distributing snowfall over mountainous terrain, as does open water to force lake-effect snows. These effects are responsible for very sharp gradients in snowfall rates and persistence, but both processes are difficult to quantify. High gradients of snowfall require dense gauge networks to accurately determine the snowfall distribution and dense gauge networks are not feasible for mountainous terrains or even lake-effect snows that often occur in remote regions. Compounding on this issue is the poor accuracy and consistency of snowfall gauges and their associated ancillary instrumentation and windshields (Rasmussen et al. 2012). Determining snowfall and SWE on the ground at global scales is equally challenging due to the relative size of snow gauges compared to the extent of seasonal snow cover (roughly $47 \times 10^{6} \mathrm{~km}^{2}$ ) and the high spatial variability of snow (Robinson and Frei 2000). Many methods have been used to distribute point scale snow measurements to gridded estimates of snow. Binary regression trees and general additive models (GAMs) both perform well in identifying nonlinear relationships of snow depth and physical predictor variables (Balk and Elder 2000; Molotch et al. 2005; López-Moreno and NoguésBravo 2006). Fassnacht et al. (2003) and Dawson et al. (2016) used linear regression and piecewise linear regression, respectively, to distribute Snowpack Telemetry (SNOTEL) snow depth measurements across different elevation ranges. These methods have shown success in producing gridded estimates of snow depth that are consistent with observations; however, they are not constrained by the amount of initial snowfall at the gauge site. Parameter-Elevation Regressions on Independent Slopes Model (PRISM) is considered to be a high-quality precipitation dataset in the mountains for the 
contiguous United States (Daly et al. 1994). PRISM uses a climate-elevation regression technique to distribute climatological precipitation data observed mostly by National Weather Service Cooperative Observer Program (COOP) precipitation gauges. Lundquist et al. (2015) showed the PRISM precipitation spatial patterns can disagree by up to $50 \%$ from observations when synoptic conditions deviate from normal.

Reanalysis products provide a complete description of the water budget, thereby linking the snowfall and snow on the ground, but there is uncertainty in the representation of snow in these products (Broxton et al. 2016). Bosilovich et al. (2008) found a majority of widely used reanalyses produce more January precipitation than the Global Precipitation Climatology Project (GPCP) for Northern Hemisphere land. Hancock et al. (2014) found three reanalysis forcing datasets underestimate cumulative snowfall by roughly $20 \mathrm{~mm}$ compared to the peak SWE amount in the GlobSnow product, a European Space Agency (ESA) hybrid passive microwave radiometer and in situ SWE dataset. While the reanalyses used in these studies are shown to have biases, the uncertainties in the GPCP and GlobSnow products also impact the findings. Specifically, both GPCP and GlobSnow have limitations in mountainous regions due to the lack of constraints normally provided by in situ observations. While reanalyses provide a global estimate of snow, there is a large spread in forcing data, model parameterizations, snow dynamics, and land surface models that compose each dataset that make it difficult to choose a "best" dataset (Reichle et al. 2017).

In the last few decades, remote sensing has substantially increased the community's knowledge of variables important to Earth's water cycle (Cui et al. 2019; Levizzani and Cattani 2019). Levizzani and Cattani (2019) and Levizzani et al. (2011) highlight issues impeding accurate remote sensing of snowfall, but suggest there is a framework for future improvements. Spaceborne passive microwave (PMW) instruments are attractive from a global snow perspective because they interact directly with the snow crystals-whether in the air or on the ground, have the ability to make observations through clouds both day and night, and have relatively frequent revisit times at high latitudes. PMW instruments have been operating on spaceborne platforms since 1978 and, therefore, offer a long time series of data. Snowfall and SWE algorithms both rely on the ice scattering properties of snow crystals to detect and estimate snow particles falling through the atmosphere or on the ground. Yet, the algorithms currently operate independently of each other and, to our knowledge, have not been analyzed together. The PMW snow community created algorithms that tried to separate the snowfall and surface snow signals by using microwave frequencies that are less sensitive to the surface and atmosphere, respectively. For example, the snowfall algorithm relies heavily on high-frequency channels that are less sensitive to the surface whereas the SWE algorithm relies on lowerfrequency channels that are less sensitive to the atmosphere.

To use a broader spectrum of available microwave channels to characterize snowfall, Ebtehaj and Kummerow (2017) and Takbiri et al. (2019) used a $k$-nearest neighbor approach to separate microwave brightness temperature (TB) signatures within different surface classes to better understand TB patterns for snowfall detection. Their methods were able to detect snowfall over snow covered regions with probabilities as high as 0.8 . Even when correctly identified, snowfall algorithms must make assumptions about the atmospheric and snowpack properties that affect the microwave radiation, which introduces a large source of uncertainty within the snow estimates. For example, Shige et al. (2013) showed that PMW precipitation retrievals underestimate precipitation within shallow orographic systems. The ice scattering signal in these cases seems to be largely masked by supercooled water present in many of these systems (Liu and Seo 2013). Perhaps for similar reasons, Cao et al. (2018) found that Integrated Multisatellite Retrievals for GPM (IMERG) underestimated cold season precipitation in the Olympic Mountains by $57 \%$.

PMW SWE algorithms make assumptions about snow density, snow grain characteristics, and the impact of vegetation that often exists above the snow layer. Even if properly modeled, these snow and vegetation properties are rarely known in current retrievals. Kelly (2009) showed the RMSE of the AMSR-E snow depth algorithm compared to Northern Hemisphere WMO station data was about $20 \mathrm{~cm}$ for forested and nonforested pixels. Tedesco and Jeyaratnam (2016) used an updated algorithm to show a reduction in RMSE values against WMO stations, but with a correlation of less than 0.5.

As noted above, there are issues with both snow algorithms that make it difficult to accurately estimate snowfall and SWE. Hydrologically, SWE is more important than snowfall, but must be constrained by the amount of initial snowfall, which is currently not a requirement for the PMW snow products. It is therefore straightforward to assess the degree of consistency between the initial snowfall and subsequent SWE. Snow redistribution processes do occur, but for the purpose of this paper, consistency is defined as the ability of snowfall estimates to physically produce SWE estimates (e.g., liquid snowfall > SWE). The consistency framework thus follows this definition. In this study, we link PMW estimates of snowfall and SWE in order to identify regions that appear in relatively good agreement as well as regions where lack of consistency points to problems with one or both of the snow products. Specifically, we use the Advanced Microwave Scanning Radiometer for Earth Observing System (AMSR-E) instrument because it was the only instrument operationally producing both snowfall and SWE products during the time period of interest. A physically based snow model, SnowModel, is employed to handle the snow evolution that is necessary to assess consistency between snowfall and SWE. This experiment would be the first to analyze PMW snowfall and SWE together and is expected to offer insights into the strengths and weaknesses of the AMSR-E snow products. Given the independent nature of the current snow algorithms, it is not expected that the snow products be consistent with each other in all regions. Furthermore, independence will allow for the assessment of using AMSR-E snowfall to estimate SWE rather than the PMW SWE estimates.

The remainder of the paper is outlined as follows. Section 2 describes the snow data to be evaluated and SnowModel. Section 3 outlines the experimental setup. Section 4 discusses 
the results of the experiment presented in section 3 . In section 5 we connect the snow consistency to information content issues for the snowfall and SWE algorithms.

\section{Data description}

The following sections describe the AMSR instrument, as well as the snowfall, SWE, and the snow model used to connect the two products in a physically consistent way. The section ends by describing some well-known climatologies of SWE that are used to compare the AMSR-E products.

\section{a. AMSR-E}

\section{1) INSTRUMENT CHARACTERISTICS}

The AMSR-E is a 12-channel, six-frequency, conically scanning, passive microwave radiometer aboard NASA's Aqua spacecraft. AMSR-E operated from 2002 to 2011 in a sunsynchronous polar orbit with equator overpass times of 0130 and 1330 UTC. The instrument measures microwave TBs between 7 and $89 \mathrm{GHz}$ from the natural emission of microwave radiation by the underlying surface and atmosphere. Geophysical variables related to Earth's surface and water cycle, such as sea surface winds, sea surface temperature, sea ice concentration, snow water equivalent, and soil moisture, as well as water vapor, cloud water, and precipitation rate are retrieved from the sensor.

Of importance to this study is snowfall and snow water equivalent; both archived at the National Snow and Ice Data Center (NSIDC). The products continue to evolve with products transitioning to Advanced Microwave Scanning Radiometer 2 (AMSR2), but also through efforts to unify the AMSR-E and AMSR2 retrievals, or Advanced Microwave Scanning Radiometer Unified (AMSR-U) in NSIDC parlance. AMSR-E and its successor, AMSR2, are the only operational NASA satellitebased measurements of SWE available. This study used the Goddard Profiling (GPROF) algorithm for precipitation estimates and the Kelly (2009) algorithm for SWE estimates. Each product is explained here for completeness.

\section{2) AMSR-E SNOWFALL}

Passive microwave retrievals of precipitation rely on absorption, emission, and scattering interactions with hydrometeors and water vapor. Frequencies below $20 \mathrm{GHz}$ are sensitive to absorption and emission from hydrometeors and frequencies above $60 \mathrm{GHz}$ are sensitive to scattering from hydrometeors. Higher-frequency channels $(>90 \mathrm{GHz})$ provide more information on snow precipitation through ice scattering.

The GPROF algorithm has a two-decade-long history of retrieving surface precipitation from passive microwave observations (Kummerow et al. 1996). GPROF is a fully parametric, Bayesian retrieval method that properly weights an a priori database of precipitation profiles and TBs that are radiometrically consistent with observed TBs. After the construction of the a priori database, a Bayesian inversion methodology is used to solve for the most likely precipitation rate. Ancillary data consisting of 2-m temperature, total column water vapor, and surface classes are used to group precipitation profiles into specific regimes. AMSR-E uses GPROF to estimate precipitation.
The creation of the GPROF a priori database for snowcovered land surfaces uses a different approach than the other land surface types within the retrieval algorithm (Passive Microwave Algorithm Team 2017). Instead of using the dual frequency radar aboard the Global Precipitation Mission (GPM) to construct a priori databases, GPROF uses precipitation data from the Multi-Radar Multi-Sensor (MRMS) product for snow covered surfaces. This was done because the GPM radars are limited to a $12-\mathrm{dB} Z$ sensitivity that affects snowfall more than liquid precipitation due to the lower dielectric constant of ice. The inclusion of MRMS for snowcovered surfaces improved on the low snowfall bias in previous versions of GPROF (Passive Microwave Algorithm Team 2017). The accuracy of the retrieval is then placed on MRMS, which is known to underestimate daily snowfall accumulation (Wen et al. 2017). This database is created by matching the MRMS precipitation pixels with coincident radiometer footprints for snow-covered surfaces. The four snow land surface classes in GPROF have identical channel sensitivities and therefore, in practice, the Bayesian inversion does not differentiate among snow surface classes and applies the same scheme to the snow classes.

\section{3) AMSR-E SNOW WATER EQUIVALENT}

Snowpack is defined to be the mass of snow on the ground that has been compressed by its own weight and the morphology of the snowpack is sensitive to the surrounding meteorological regime. Ulaby and Stiles (1980) identified the capability of using passive microwave sensors for monitoring snow depth and SWE. A microwave instrument above the snowpack will measure the naturally emitted surface radiation that is attenuated by the snowpack. Attenuation by the snowpack can be reduced, in its simplest form, to scattering by individual snow grains that have unique shapes and sizes. Thus, the number of snow grains, or scatterers, along the path can be related to the snow depth. Chang et al. (1987) showed scattering by a snowpack increases with grain size and frequency. For example, the authors showed a TB difference of approximately $75 \mathrm{~K}$ between a snowpack with snow grains of 0.3 and $0.5 \mathrm{~mm}$ in radius. Given the interactions of microwave radiation within the snowpack, the measured TB is inversely proportional to the snow depth in dry conditions. However, the measured TB varies drastically depending on the snow grain size, snow depth, snow density, and liquid water content within the snow. A small amount of liquid water within the snowpack due to rain on snow or snowmelt severely inhibits the ability to detect a scattering signature, and therefore, snow depth.

Historically, SWE algorithms relate the TB difference between a scattering sensitive channel $(36 \mathrm{GHz})$ and nonscattering sensitive channel $(19 \mathrm{GHz})$ to snow depth using linear regression (Chang et al. 1987; Foster et al. 1997; Sturm et al. 2010). The regression coefficient is ultimately related to snow grain size. The SWE algorithm in this study uses a similar linear regression technique, but includes more complexity surrounding issues regarding vegetation, snow grain size, and deep snowpacks (Kelly 2009). This algorithm is hereinafter referred to as K2009. K2009 is composed of four parts: snow detection, snow depth estimation, snow depth retrieval, and 
snow depth conversion to SWE. Snow detection consists of screening for rainfall scattering signatures which typically have higher TBs than snow on the ground at $36 \mathrm{GHz}$. K2009 found a TB threshold of 245 and $255 \mathrm{~K}$ at the $36-\mathrm{GHz}$ horizontal and vertical polarizations, respectively, to best screen for rain scattering signatures. Snow depth estimation is determined by TB difference between the $10-$ and $36-\mathrm{GHz}$ channels. A TB difference greater than $0 \mathrm{~K}$ indicates the presence of a nonscattering scene, which is further tested for the case of shallow snow. The presence of a scattering scene triggers the snow depth retrieval algorithm to estimate snow depth using linear regression against the TB difference. Regression coefficients are computed from the polarization difference at 18 and $36 \mathrm{GHz}$ to account for changing snowpack characteristics. Vegetation information is included in the retrieval to help isolate the measured TB to snow-only emission. Finally, the estimated snow depth is converted to SWE using a spatial varying snow density dataset described in Sturm et al. (2010).

\section{b. Snow Model}

SnowModel is used to provide a physical link between the initial snowfall and subsequent SWE measured by ASMR-E through snow evolution. SnowModel is a spatially distributed snow-evolution model that includes the first-order physics required to simulate snow processes in landscapes and climates where snow occurs (Liston and Elder 2006). Processes simulated include snow accumulation; snow density evolution; snowpack compaction, sublimation, and melt; forest canopy snow interception, unloading, and sublimation; and winddriven snow redistribution and sublimation. Required inputs are temporally varying fields of meteorological forcing data and spatially varying fields of topography and vegetation. SnowModel has been used extensively in different meteorological and snow regimes (e.g., Liston and Sturm 1998; Liston et al. 1999; Hiemstra et al. 2002; Liston and Winther 2005).

SnowModel is a collection of five coupled submodels that each simulate different physical processes known to drive snow evolution: MicroMet, EnBal, SnowPack, SnowTran-3D, and SnowAssim. At each time step, meteorological forcing data (global reanalysis in this study) are distributed over the domain using MicroMet and then at each grid cell the model 1) performs near-surface energy balance calculations using EnBal, 2) evolves the snowpack defined by the melt and precipitation input using SnowPack, and 3) transports snow by wind-driven processes using SnowTran-3D. Following the completion of the simulation, the snow assimilation submodel, SnowAssim, can be used to constrain the modeled SWE output through corrections to the precipitation forcing that will ultimately produce the assimilated SWE.

For this study, SnowAssim is the most important submodel as it allows the assimilation of observed or modeled SWE data to provide the model constraints. Snowfall has been shown to lead to the largest errors in modeling snow on the ground (Liston and Sturm 2004; Raleigh et al. 2016). Therefore, SnowAssim modifies the snowfall forcing, which is then retroactively applied throughout the snow accumulation season. The modified snowfall is used in a second SnowModel simulation that will produce the assimilated SWE distribution.
Most importantly, the modified snowfall is used to assess the consistency between the observed AMSR-E snowfall and the snowfall necessary to produce the AMSR-E SWE.

\section{c. Canadian Meteorological Centre snow analysis}

The Canadian Meteorological Centre (CMC) SWE dataset is used as an additional comparison dataset to AMSR-E (Brasnett 1999). CMC is a hybrid modeling-observation snow depth and SWE dataset that is widely used and has been described as the best available observational snow dataset for the Northern Hemisphere (Toure et al. 2016). The snow depth output is produced using daily in situ snow depth observations that are optimally interpolated onto a first-guess snow depth field estimated by a simple snow model. The snow model is driven by meteorological data from the CMC Global Environmental Multiscale (GEM) forecast model and in situ snow depth data are collected from surface synop stations, METAR stations, and special aviation reports from the WMO. Snow depth is converted to SWE using a monthly climatology of snow density (Brown and Mote 2009). CMC is used in this study because it allows the comparison of remotely sensed and modeled SWE to a mostly observational product.

\section{Experimental setup}

To assess the consistency between AMSR-E snowfall and SWE, we performed SnowModel simulations with assimilation for the Northern Hemisphere between July 2003 and June 2011.

Simulations are run on a $25-\mathrm{km}$ Equal-Area Scalable Earth (EASE) grid that includes a variety of meteorological, snowpack, and vegetation regimes. A simulation year is defined to be from July of a specific year to June of the next year (e.g., July 2004-June 2005). Two SnowModel simulations with assimilation are run: one for AMSR-E and one for CMC. All available AMSR-E SWE, AMSR-E precipitation, and CMC data were obtained for the simulation period and resampled to the EASE-grid using the Geospatial Data Abstraction Library (GDAL) command line tool. A temperature threshold of $2^{\circ} \mathrm{C}$ determined by the SnowModel meteorological forcing data is used to differentiate between liquid and solid precipitation for both AMSR-E and SnowModel (Auer 1974). AMSR-E and CMC data were averaged monthly to better compare the general time series of snowfall and SWE. AMSR-E daily data have missing data due to the polar orbit of the satellite while CMC SWE data are only available on monthly time scales. AMSR-E SWE data are especially noisy from day to day, which can propagate into the assimilation model and produce erroneous SWE values. To better compare snowfall against SWE, AMSR-E snowfall is converted to an accumulated snowfall throughout each simulation year.

The Modern Era Retrospective Reanalysis of the Atmosphere Version 2 (MERRA-2) meteorological data are used to force SnowModel. MERRA-2 surface pressure, 10-m air temperature, 10-m specific humidity, and bias corrected total precipitation (M2CORR) were obtained for the simulation period and resampled to the EASE-grid to be used as input to SnowModel. Simulations were run at 3 -h time steps, which sufficiently captured the diurnal cycle of snow evolution. 
AMSR-E Observed SWE

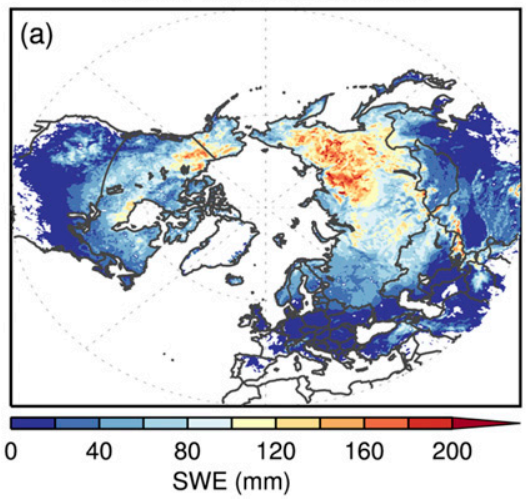

ratio (CMC vs. AMSR-E)

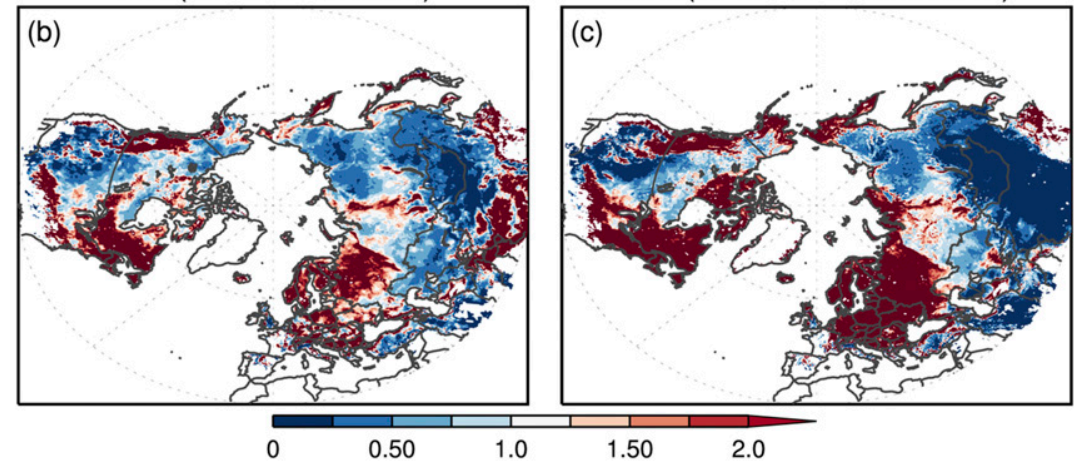

FIG. 1. Average 2003-11 February (a) AMSR-E SWE, (b) ratio between CMC and AMSR-E SWE, and (c) ratio between MERRA-2 and AMSR-E SWE.

For this study, the submodel SnowTran-3D was not employed, and snow transport processes were not simulated. Given the $25-\mathrm{km}$ grid spacing of this study, this is not expected to significantly impact the results. Average grid cell elevation information is provided by the United States Geological Survey Global Multiresolution Terrain Elevation Data (GMTED2010). Vegetation data are provided by the European Space Agency's GlobCover dataset and reclassified into the SnowModel land cover and height specifications. Both datasets are resampled to the EASE-grid.

Hedrick et al. (2018) demonstrated that assimilating snow depth data from airborne lidar for one date near the peak SWE was sufficient to correct a snow model's accumulation errors. We felt it was necessary to constrain SnowModel throughout the accumulation and ablation seasons and therefore monthly averaged AMSR-E and CMC SWE were assimilated using SnowAssim on the fifteenth day of October, December, February, and April. For the remainder of the paper, data output by SnowModel will be referred to as inferred data (e.g., inferred AMSR-E Snowfall). SnowModel data are output on daily time scales and averaged monthly to be compared to the observations. Similarly to AMSR-E, snowfall is reported as snowfall accumulation for a better comparison to SWE. Greenland and the Himalayas are removed from the analysis due to masks within the products used (e.g., Greenland mask in CMC).

\section{Results}

\section{a. SWE evaluation}

Large-scale deficiencies in AMSR-E SWE have been previously noted (Clifford 2010; Lee et al. 2015; Vuyovich et al. 2014; Wrzesien et al. 2017; Dawson et al. 2018). These deficiencies are briefly discussed here for context and completeness within the consistency framework. As can be seen from Fig. 1, AMSR-E SWE is significantly higher than CMC and MERRA-2 over Siberia and northwestern Canada. This phenomenon has been documented to be a high bias in AMSR-E due to larger than average snow grain sizes $(2-5 \mathrm{~mm})$ within the snowpack (Tedesco and Jeyaratnam 2016). These cause excessive scattering of microwave radiation that the algorithm misinterprets as additional snow depth. The high bias in AMSR-E SWE extends equatorward into East Asia but the causes for this are less clear. In contrast, AMSR-E shows significantly less SWE than CMC or MERRA-2 in many mountainous regions including the western United States, Scandinavian Mountains, and Ural Mountains. This was expected as the AMSR-E SWE algorithm saturates at snow depths values near $600 \mathrm{~mm}$ (Tedesco and Narvekar 2010), which is common snow depth in mountain ranges with seasonal snow. AMSR-E also underestimates SWE compared to CMC and MERRA-2 in northeastern North American and eastern Europe. In these regions, however, there is also a significant disagreement between CMC and MERRA-2. Interestingly, these are both regions where the CMC product has a relatively higher density gauges used in the product creation.

CMC and MERRA-2 produce expected regional spatial patterns with higher SWE in the mountains and northern latitudes. However, there are discrepancies between products at more local spatial scales (i.e., within the western United States). We do not consider any of the SWE products as truth to be used for verification, but rather as a platform to identify regions of confidence and concern for AMSR-E. Differences in the products can highlight underlying physical characteristics of the snow evolution process that can be used to improve the SWE algorithm.

\section{b. Snowfall evaluation}

Average AMSR-E snowfall accumulations are generally less than $120 \mathrm{~mm}$ (Fig. 2a), which for some regions, is less than the amount of SWE from any of the three estimates of SWE shown in Fig. 1. The regions of largest underestimation occur in mountainous and high-latitude regions, which is similar to the regions of underestimation shown by the AMSR-E SWE product. Mountain snowfall and SWE is a large concern given North American mountains contain roughly $60 \%$ of the continent's SWE while seasonally snow-covered mountains are roughly $31 \%$ of Earth's snow-covered area (Wrzesien et al. 2018, 2019).

The previous section highlighted the large-scale deficiencies in the AMSR-E SWE product when compared to MERRA-2 
AMSR-E Accumulated Snowfall

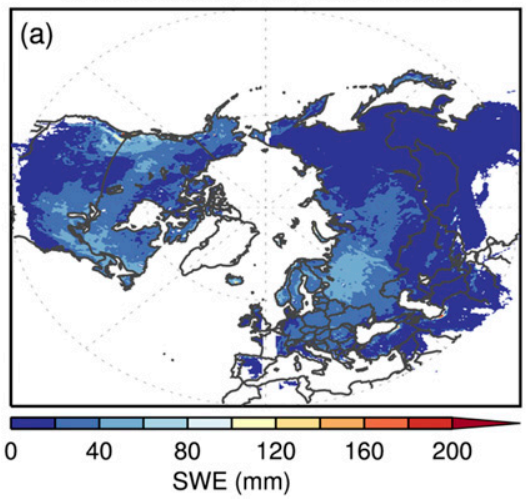

ratio (CMC vs. AMSR-E)

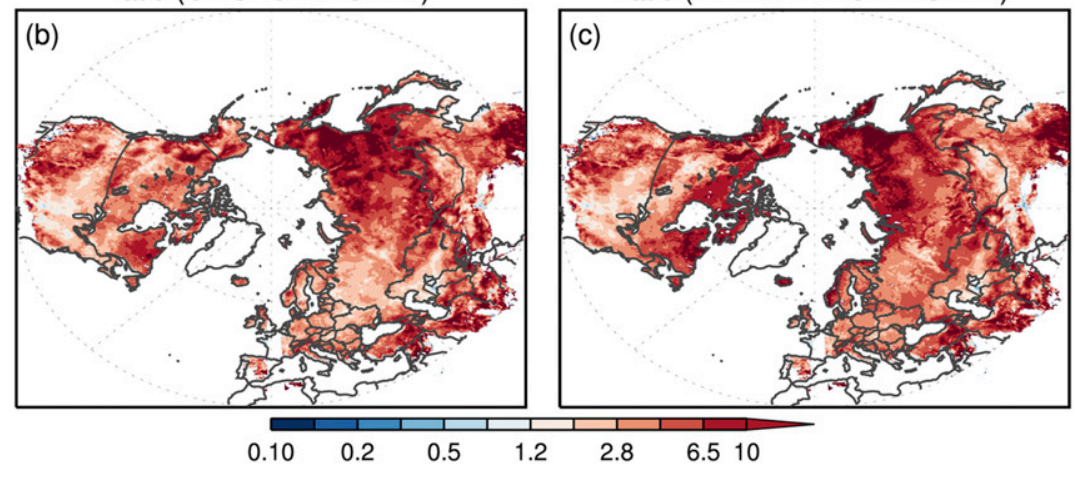

FIG. 2. Average 2003-11 February (a) AMSR-E accumulated snowfall, (b) ratio between inferred CMC and AMSR-E accumulated snowfall, and (c) ratio between MERRA-2 and AMSR-E accumulated snowfall.

and CMC SWE. Figure 2a shows the accumulated AMSR-E snowfall averaged during the month of February for the period of 2003-11. It is evident AMSR-E snowfall is biased low. However, the snowfall spatial pattern is reasonable with a relatively larger amount of accumulated snowfall in mountainous and high-latitude regions. It is therefore straightforward to assess if AMSR-E snowfall is a more useful metric to estimate SWE than the AMSR-E SWE product itself. Figure 2 shows the average February AMSR-E accumulated snowfall compared to the inferred CMC and MERRA-2 accumulated snowfall. In order for AMSR-E to capture more reasonable snowfall magnitudes, large multiplicative bias ratios would need to be applied almost to the entire Northern Hemisphere. In some cases, a multiplicative bias ratio of an order of magnitude would need to be applied. The low biases seen for February (Fig. 2) are also seen throughout the rest of the winter season (not shown) indicating the AMSR-E snowfall algorithm has significant issues estimating snowfall magnitudes for all surface and meteorological conditions. The accumulated snowfall from AMSR-E is currently in no position to be used to estimate SWE without applying large corrections to the snowfall product.

\section{c. AMSR-E snow consistency}

The AMSR-E snow products are shown to have large biases when compared to CMC and MERRA-2. It is important to assess the consistency between the snow products as a context for future development of the snow products. Figure 3 shows the average February spatial biases for 2003-11 between the AMSR-E observed snowfall and the inferred snowfall from AMSR-E SWE in an attempt to asses if any regions show good consistency. This comparison allows consistency checks in the snow products because of the assimilation submodel in SnowModel. While the AMSR-E snow products, particularly based upon the previous results, would hardly be expected to show consistency, some regions are within $20 \mathrm{~mm}$ of consistency. In parts of the northern Rocky Mountains, Quebec, and eastern Europe, AMSR-E snowfall is within $20 \mathrm{~mm}$ of the snowfall inferred from the SWE observations. However, in all of these regions, Fig. 1 shows that AMSR-E significantly underestimates SWE compared to MERRA-2 and the CMC
SWE products. Consistency in these regions appears to be produced by both products significantly underestimating snow rather than any physical consistency. There are a few regions, most notably Siberia, where AMSR-E significantly overestimates SWE and that shows up in the bias map as well. In Siberia, snowfall and inferred snowfall differ by more than a factor of 10. The Alaska-Canadian border into the Hudson Bay is another region of higher inconsistency. Derksen and MacKay (2006) confirmed the larger values of SWE are consistent with ground data from field campaigns.

The accuracy of both snow products is expected to change as the winter season progresses. Here the consistency between the observed and inferred accumulated snowfall, averaged for each month during the study period, is analyzed (Fig. 4). Similar to snow water storage (SWS) in the hydrology community, the total snowfall volume (SfV) for the study domain is used to assess the consistency. Throughout the time series,

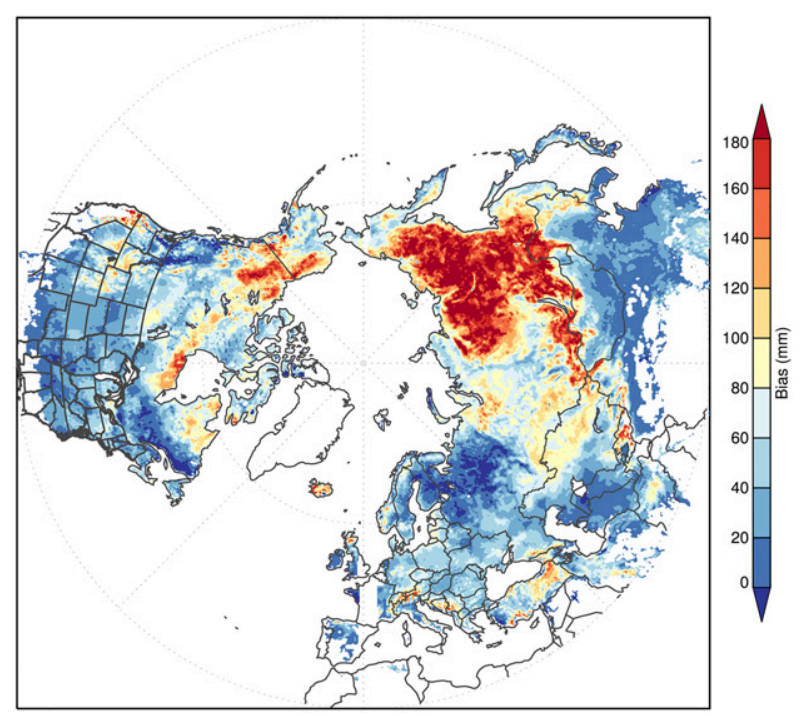

FIG. 3. Average February AMSR-E consistency bias defined as the difference between accumulated AMSR-E inferred snowfall using SnowModel and accumulated observed AMSR-E snowfall. 
$\mathrm{NH}$ Accumulated Snowfall Volume
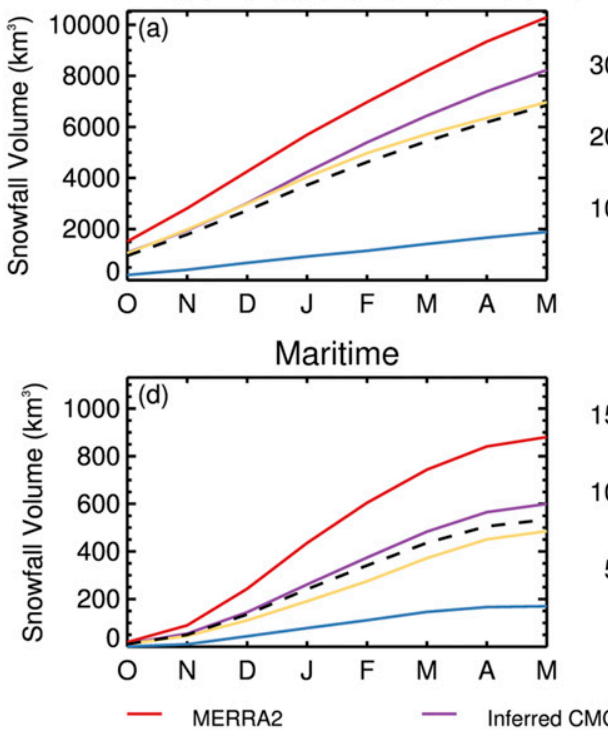

Tundra
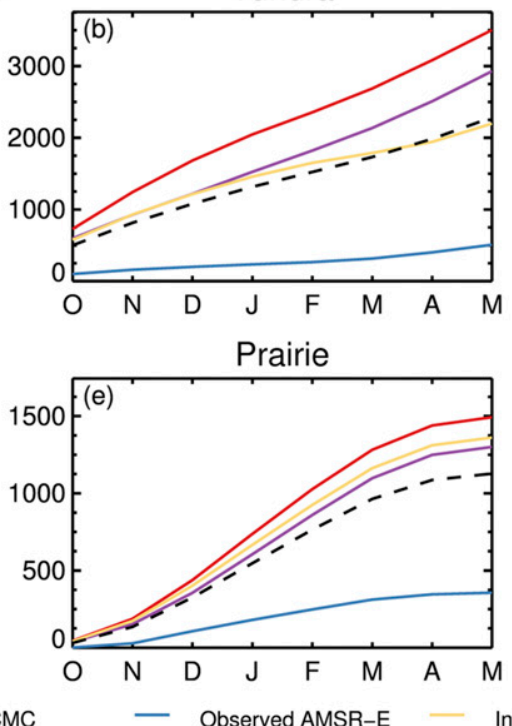

Taiga
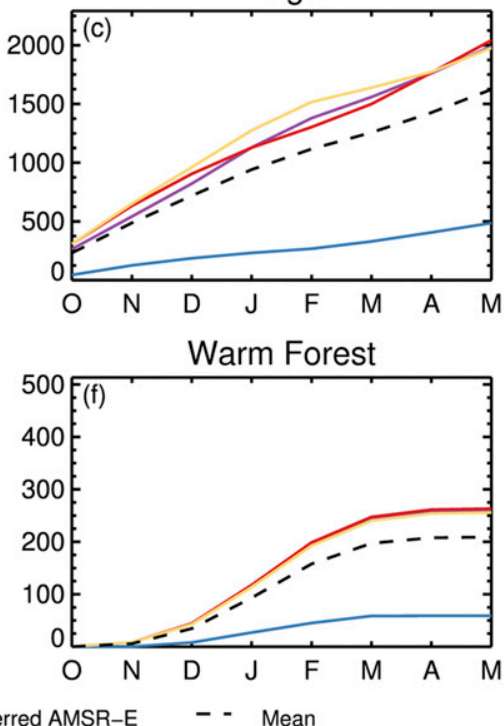

FIG. 4. (a)-(f) Time series of accumulated snowfall volume for MERRA-2, CMC, inferred AMSR-E, and observed AMSR-E averaged for each month during the 2003-11 period. Snow climate class from Sturm et al. (1995) are used to categorize snowfall volume by meteorological regime. In (f), the inferred CMC curve lies below the MERRA2 and inferred AMSR-E curves.

MERRA-2 accumulated SfV is the largest, while observed AMSR-E is always the smallest. MERRA-2 is as high as $600 \%$ greater than the observed AMSR-E SfV. The inferred AMSR-E accumulated SfV tracks closely with CMC until early December before diverging to lower SfV the remainder of the winter season. Evident in Fig. 4a is that the observed AMSR-E $\mathrm{SfV}$ is biased low and increases linearly throughout the winter season. Surface conditions are known to impact snowfall retrievals (Takbiri et al. 2019), but there is no noticeable evidence in the observed AMSR-E SfV of this phenomenon pointing to other fundamental issues with the current algorithm. The low bias in the observed AMSR-E reinforces it is currently not a useful metric to be used to estimate SWE without applying large corrections. The low bias in the observed AMSR-E SfV throughout the winter season reinforces the results in section $4 \mathrm{c}$.

Sturm et al. (1995) developed a physically based seasonal snow cover classification system that can easily be applied to global snow regimes. The snow cover classifications have been recently updated to provide a higher-resolution classification dataset as well as alter a couple of the snow classes to better represent mountain snowpack (G. E. Liston 2019, personal communication). The updated snow classes include tundra, taiga, warm forest, maritime, prairie, and ephemeral snow cover. Additional information on the formation of these snow classes can be found in Sturm et al. (1995) and Table 1 describes each snow class. The snow climate classes are used to separate SfV into different snow regimes (Figs. 4b-f). For all snow climate classes, AMSR-E observed SfV is the smallest. The inferred AMSR-E tracks well with MERRA-2 and CMC for the warm forest and prairie snow classes, which are relatively cold with moderate snowfall meteorological regimes. The AMSR-E SWE and snowfall algorithm were shown to be poor in maritime regimes, and the time series of SfV for the inferred and observed AMSR-E snowfall are both below the mean throughout the winter season. The AMSR-E inferred SfV has a different temporal pattern for the tundra and taiga snow classes. The diverging pattern observed in the total SfV is driven by the tundra snow class. The tundra snow class is a cold, wind-blown regime with larger snow crystals where the AMSR-E SWE algorithm, and therefore inferred snowfall, perhaps saturates earlier in the season. For the taiga snow class, the inferred AMSR-E SfV tracks with MERRA-2 and CMC throughout the season likely corresponding to large grain sizes causing a high bias in the AMSR-E SWE algorithm.

\section{Discussion}

The results in section 4 show that both snowfall and SWE measured by AMSR-E are poor compared to CMC and MERRA-2. Furthermore, snowfall from AMSR-E is not a more useful metric to estimate SWE than the AMSR-E SWE product without large corrections. The SWE and snowfall algorithms each have errors related to the physical processes occurring within snowfall production and the snowpack. The physical processes are related to small-scale processes that are sensitive to changes in the surrounding environment. From a PMW perspective, the small-scale processes can have a large impact on the measured TBs. Here we will discuss processes affecting the SWE and snowfall algorithms that can be related to the inconsistency of the AMSR-E snow budget. We do not improve upon the algorithms, but rather highlight the necessity of additional information within the algorithms that can improve future PMW snow algorithms and snow consistency.

\section{a. Snow climate classes}

The snow climate classes discussed in section $4 \mathrm{c}$ can offer physical insight into the behavior of observed TBs for a given 
TABLE 1. Sturm et al. (1995) snow climate class descriptions. The warm forest snow class was added in the version by G. E. Liston (2014, unpublished manuscript).

\begin{tabular}{|c|c|c|c|c|c|}
\hline Snow cover class & Description & Depth range $(\mathrm{cm})$ & Bulk density $\left(\mathrm{g} \mathrm{cm}^{-3}\right)$ & Grain size $(\mathrm{mm})$ & No. of layers \\
\hline Tundra & $\begin{array}{l}\text { A thin, cold wind-blown snow. Usually } \\
\text { found above or north of tree line. }\end{array}$ & $10-75$ & 0.27 & 2.0 & $0-6$ \\
\hline Taiga & $\begin{array}{l}\text { A thin to moderately deep low-density } \\
\text { cold snow cover. Found in cold climates } \\
\text { in forests where wind, initial snow } \\
\text { density, and average winter air tem- } \\
\text { peratures are all low. By late winter } \\
\text { consists of } 50 \%-80 \% \text { depth hoar. }\end{array}$ & $30-120$ & 0.22 & $3-5$ & $>15$ \\
\hline Warm forest & $\begin{array}{l}\text { An intermediate to cold deep snow cover. } \\
\text { Often alternate thick and thin layers. } \\
\text { Melt features occur but are generally } \\
\text { insignificant. }\end{array}$ & $75-250$ & 0.30 & $2-3$ & $>15$ \\
\hline Maritime & $\begin{array}{l}\text { A warm, deep snow cover. Melt features } \\
\text { are very common. Course-grained } \\
\text { snow due to wetting ubiquitous. }\end{array}$ & $75-500$ & 0.31 & $2-3$ & $>15$ \\
\hline Prairie & $\begin{array}{l}\text { A thin moderately cold snow cover with } \\
\text { substantial wind drifting. }\end{array}$ & $0-50$ & 0.29 & $1-2$ & $<5$ \\
\hline Ephemeral & $\begin{array}{l}\text { A thin, extremely warm snow cover. } \\
\text { Often consists of a single snowfall that } \\
\text { melts away. }\end{array}$ & $0-50$ & No data & $<2$ & $1-3$ \\
\hline
\end{tabular}

snowpack climate regime. Other studies have used the snow climate classes as a physical descriptor to better estimate SWE from PMW instruments, but did not place the SWE estimates within the snow consistency framework (Josberger and Mognard 2002; Cordisco et al. 2006; Derksen et al. 2010). To better understand the AMSR-E TB response to the snow climate classes, the nearest snow climate class is collocated with AMSR-E pixel information for one winter season spanning October 2004-February 2005. The monthly time period is consistent with the time period used to analyze AMSR-E snow consistency. Figure 5 shows 2D histograms of the observed TBs for snow covered pixels as a function of month. To quantify this observation space, the TBs are divided into bin sizes of $1 \mathrm{~K}$ for the $36-$ and $18-\mathrm{GHz}$ vertically polarized channels. Each grid box is assigned the snow class with the highest probability of occurrence. Kelly (2009) estimated snow is the dominant scattering signature at $36 \mathrm{GHz}$ for TBs less than $255 \mathrm{~K}$, which is used as an upper threshold in our analysis. Data points above the 1:1 line indicate scattering is occurring.

As winter progresses and snow accumulates and evolves (metamorphizes), there is a shift in TBs to a more scattering regime. The increase in scattering signature is well defined in the taiga, prairie, and warm forest snow classes. The scattering signature is present to a lesser degree for the tundra and maritime snow classes, and is perhaps due to saturation and liquid water effects on the TBs at both frequencies. Throughout the snow season, TBs within the maritime snow class reside near the 1:1 line with a majority of observations below the 1:1 line, indicating scattering is not observed. The maritime snow class has ubiquitous melt features within the snowpack, which dampens the scattering signal and causes the SWE estimates to be small in the AMSR-E algorithm. A scattering signal can still occur in maritime snow (Fig. 6a) that will produce larger SWE estimates, but it is not a common feature to observe (Fig. 5). The tundra and taiga snow classes occur with the highest probability almost exclusively within the scattering regime. These snow classes are comprised of cold, dry snowpacks in which the SWE algorithm has the best performance. However, large snow grains (on the order of 2$5 \mathrm{~mm}$ ) are common in these snow regimes which increases the microwave scattering signal compared to smaller snow grains. Most notably in Siberia, the AMSR-E algorithm interprets this increased scattering signal as a larger amount of SWE (Fig. 1a), whereas CMC estimates lower SWE for the same snow regimes (Fig. 1b). Ultimately, the retrieval coefficients in the AMSR-E algorithm are unable to account for the increased grain sizes within these snow classes. Prairie and warm forest snow classes are associated with warmer TBs with the prairie snow class having a broad range of scattering characteristics. Foster et al. (2005) showed positive errors in PMW SWE estimates based on the assumption of a constant grain size increase for the tundra, taiga, and prairie (TTP) throughout the winter season consistent with the increase in TB spectral gradient shown here. Similarly, errors in SWE estimates for the maritime class are roughly constant throughout the winter season indicating low variability in TB spectral gradient due to the maritime snowpack characteristics discussed above.

Figures $6 \mathrm{a}$ and $6 \mathrm{~b}$ separates the TB response into different SWE depth categories as estimated by AMSR-E (CMC) as well as the snow climate classes. The TB response is shown as the difference between the 18 - and $36-\mathrm{GHz}$ vertically polarized channels where the filled symbol represents the mean difference for the SWE bin and the vertical bars represent one standard deviation from the mean. TBs at $36 \mathrm{GHz}$ are more sensitive to scattering and decrease faster than TBs at $18 \mathrm{GHz}$, which drives the decrease in the observed TB difference. In Fig. 6a, for all snow climate classes, the mean 

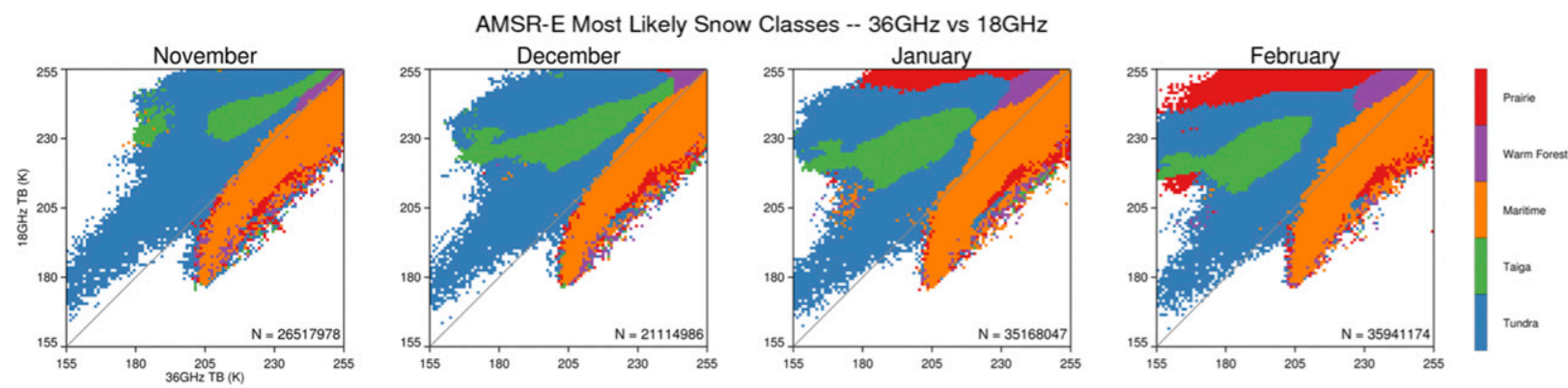

FIG. 5. Scatterplot time series of the AMSR-E 36- and 18-GHz TBs based on the snow climate classifications. The snow climate classification within a TB bin represents the highest probability snow class for that bin.

difference increases with increasing SWE depth, which is an expected result given the AMSR-E SWE algorithm is a regression of TB difference to snow depth. More importantly, the groupings of different snow climate classes represent regime dependent scattering characteristics of the snowpack. The TTP snow class average TB differences are consistently grouped closely to one and are always greater than the maritime and warm forest (MWf) snow classes likely due to the cold, dry snowpack with larger snow grains within the TTP snow classes. Interestingly, the taiga snow class TB difference is consistently higher than the tundra snow class, perhaps due to a larger influence from forest canopy microwave interactions within the taiga regime. While the AMSR-E derived SWE depth increases with greater TB difference (by algorithm design), it is clear that independent SWE depth (as evidenced by CMC SWE in Fig. 6b) is far more complex and ill-posed to the extent that the same TB differences can produce a variety of SWE depths. Using the observationally driven SWE depths of CMC, the AMSR-E TBs are unable to, by themselves, uniquely estimate varying SWE depths. Even when partitioning the TBs with the additional information of snow climate classes, this issue persists, and is likely caused by intersnow class variability as well as microwave saturation issues toward the larger SWE depths that are also clearly discernable in Fig. 6b. Increasing TB differences in the TTP snow classes near $100 \mathrm{~mm}$ of SWE is an indication of the saturation effect at $36 \mathrm{GHz}$ with increased scattering at $18 \mathrm{GHz}$. Even the TB difference between 10 and $18 \mathrm{GHz}$, used for deep snow in the AMSR-E retrieval algorithm, does not show clear sensitivity (e.g., increasing TB differences) to SWE depths above $100 \mathrm{~mm}$ for the TPP snow classes (figure not shown).

Snowpack radiative transfer studies have shown the value in modeling TBs given the snowpack characteristics. However, harsh snowpack environments do not allow for detailed in situ information of the global snowpack characteristics that would likely improve the radiative transfer computations and therefore the retrieval algorithm.

\section{b. Snowfall climate characteristics}

While it is difficult to uniquely determine from TBs alone, snowfall microphysical information may usefully constrain the SWE results. To use TB data to accurately estimate snowfall rate, realistic particle size distributions must be assumed. Field campaign and aircraft ice microphysical data have been used extensively to validate model microphysics parameterizations (Heymsfield et al. 2017). Heymsfield et al. (2013) showed ice particle size distributions are temperature dependent. For example, the diameter of ice crystals decreases with decreasing temperature with an accompanied increase in the number concentration of smaller ice particles. Ukichiro Nakaya performed the first in-depth study on snow crystal morphology in the 1930s, which now is known to be the origin of the snow crystal morphology diagram (Nakaya 1951). He showed ice crystal growth is sensitive to the temperature and water vapor supersaturation of the local environment. The original snow crystal classification work of Nakaya (1951) has been revisited to extend the database of snow crystals (Magono and Lee 1966; Kikuchi et al. 2013). Microwave radiation has complex interactions with nonspherical ice particles depending on the ice crystal shape, size, and particle distribution, as well as the presence of cloud water mixing in with the snow crystals. Isolating the snowfall retrieval to snowing clouds only, the number of variables that must be accounted for is not trivial.

Liu (2008) created an ice particle database with singlescattering properties for varying microwave frequencies, temperature ranges, ice particle sizes, and ice crystal shapes. The database is computed using a discrete-dipole approximation (DDA) of the radiative transfer for a given randomly oriented ice particle. In this section, we use the Liu ice scattering database to simulate TBs and their sensitivity to temperature changes and assumptions of the ice crystal shape. The ice crystal scattering database used is complementary to Kim (2006) and Yang et al. (2013).

We first obtained atmospheric profile information needed to simulate TBs from the Weather Research and Forecasting (WRF) Model. WRF was run for a synoptic scale snow event in the Great Plains on 26 December 2016 and all snowing pixels with a $2.0 \pm 0.1 \mathrm{~mm} \mathrm{~h}^{-1}$ of liquid equivalent snowfall for the $24 \mathrm{~h}$ period (0000 UTC 25 December-0000 UTC 26 December) were selected for analysis. WRF was used to provide more realistic profile information in order to simulate TBs while also providing different profiles for similar snowfall rates. Look-up tables (LUT) of the bulk scattering properties for snow, ice, rain, and cloud water are created for efficiency within the microwave radiative transfer code and the particle size distributions are assumed to be exponential and temperature dependent. The Eddington approximation is 

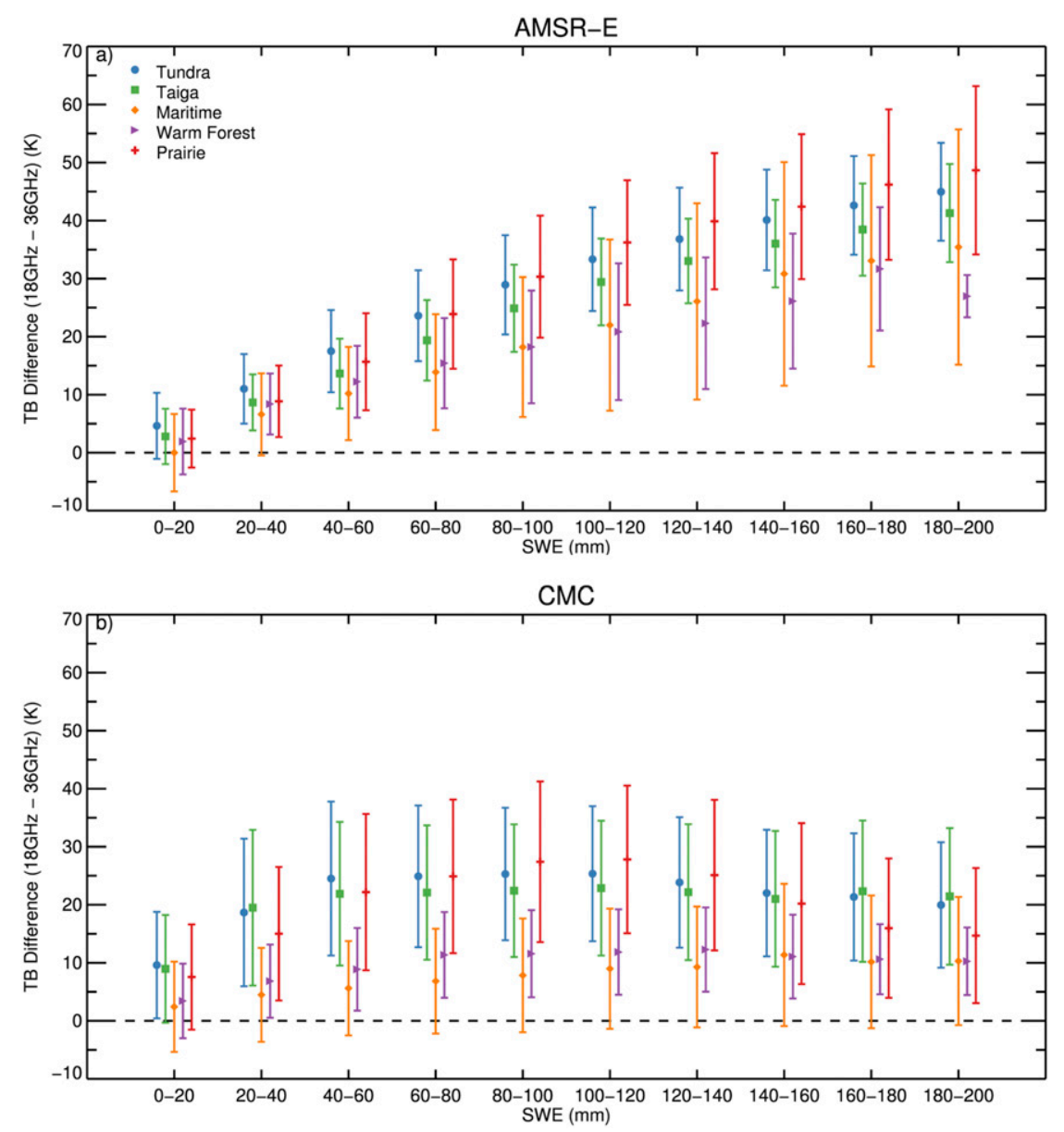

FIG. 6. Average TB differences between the AMSR-E 18- and 36-GHz channel. These channels are the main component of the AMSR-E SWE algorithm. TB differences are plotted as a function of SWE depth and Sturm et al. (1995) snow climate class. Vertical error bars indicate one standard deviation displacement from the mean TB difference.

used to solve the radiative transfer (Kummerow 1993). Figure 7 shows the average simulated TBs at $89 \mathrm{GHz}$ for an assumed particle shape and temperature profile perturbation. As can be seen, there is little sensitivity to temperature for any given ice particle shape. However, there is large sensitivity to the ice particle (density and shapes), spanning over $100 \mathrm{~K}$ for the same temperature profile and snowfall rate. Previous studies have also noted large variations in TBs for different snow crystal models (Johnson and Petty 2001; Kulie et al. 2010; Johnson et al. 2012). While it is likely a mixture of ice particle shapes and sizes are within a snowing cloud, Fig. 7 highlights the uncertainty associated with an incorrect assumption about the ice particle type.

Microphysical snowfall properties are important when considering the complex and variable interactions with microwave radiation in the context of retrieval algorithms. Modeling studies offer regional to global microphysical information to aid in retrievals. However, studies have found that WRF overpredicts the snow aloft and the size distribution compared to observations and struggles with the timing and location of snowfall (Conrick and Mass 2019; Hughes et al. 2020). It is therefore important to identify if modeled microphysics are sufficiently captured to then help constrain the snowfall retrieval to provide better consistency with PMW SWE or provide better precipitation forcing data to estimate SWE.

\section{Conclusions}

Snowfall and SWE was shown to be difficult to accurately observe using PMW retrievals. Spaceborne PMW instruments produce global snow observations at relatively high temporal resolution in regions where in situ data are not available or has high uncertainties. This study examines, to first order, the consistency between AMSR-E snowfall and SWE observations using a snow modeling system (SnowModel) to allow for a consistent comparison of the two snow products through snow evolution. This approach is novel in that it is the first study to address snowfall and SWE from a PMW instrument together within the snow budget. The goal of this study is not to validate the snow products, but rather identify strengths or deficiencies in the products that can be used for future improvement. 


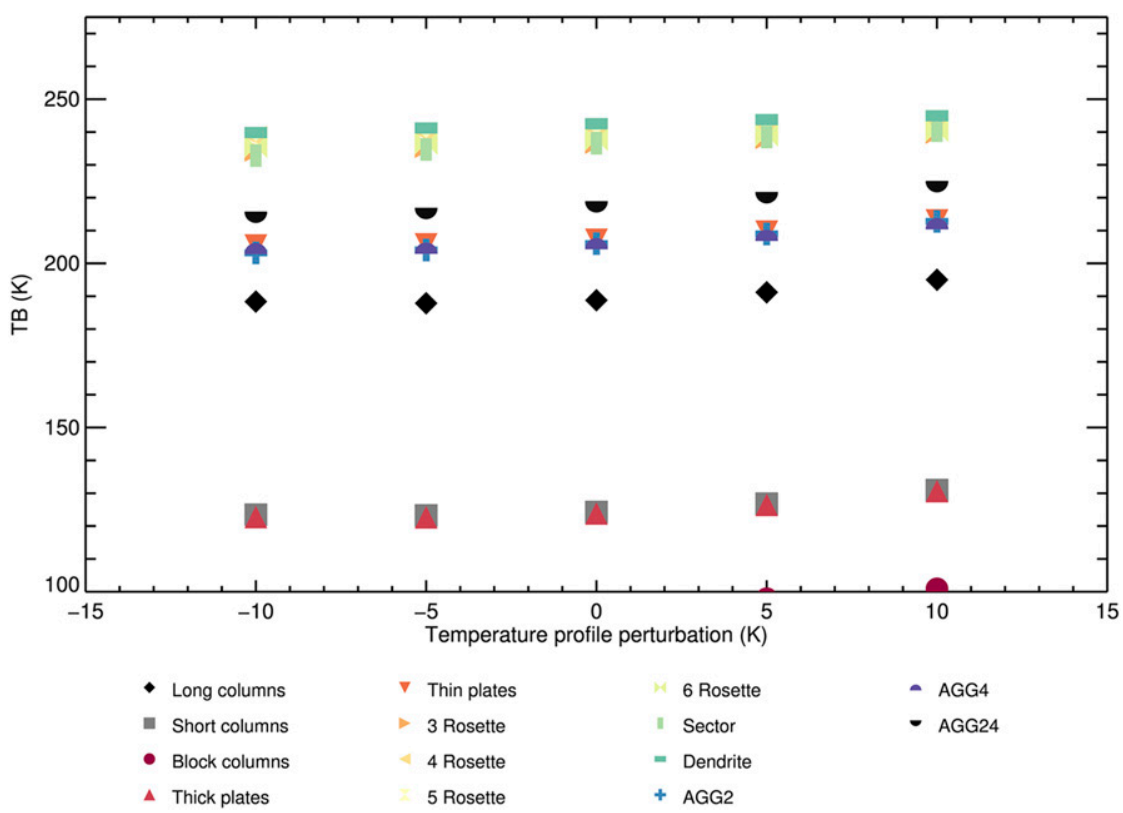

FIG. 7. Simulated TBs using WRF atmospheric profiles for a synoptic scale snow event on $26 \mathrm{Dec} 2016$. TBs are averaged for all profiles with a snowfall rate of $2.0 \pm 0.1 \mathrm{~mm} \mathrm{~h}^{-1}$ of liquid equivalent snowfall. The $x$ axis shows the amount in kelvins that the temperature profile is perturbed. The number corresponding to the rosette snowflake shape indicates the number of bullets the rosette contains. The snowflake shape AGG2 is composed of aggregates of $200-\mu \mathrm{m}$ 6-bullet rosettes, AGG4 of aggregates of 400- $\mu \mathrm{m}$ 6-bullet rosettes, and AGG24 is composed of aggregates of 200- and 400- $\mu \mathrm{m}$ 6-bullet rosettes.

We discuss how a lack of information for both the snow products hinders the ability to accurately estimate snowfall and SWE at this time.

It has been shown that AMSR-E has difficulty in accurately estimating SWE compared to CMC and MERRA-2. Both over and underestimation occur (Fig. 1), which can be associated to some degree to the local snow climate class (Figs. 5 and 6). While it may be possible to improve the algorithm by adding snow class information, Fig. 6 highlighted that, for a given SWE depth, intrasnow class variability in TBs is still a source of uncertainty. AMSR-E snowfall, on the other hand, appears to be underestimated globally with larger underestimation occurring in cold regions, high latitudes, and mountains. The consistency framework allows the assessment of using AMSR-E snowfall accumulation to estimate SWE instead of the AMSR-E SWE algorithm. Figures 2 and 4 highlighted the current snowfall product significantly underestimates snowfall in the Northern Hemisphere and would require large corrections to be a more useful metric to estimate SWE. The overall underestimation may be linked to an underestimation of MRMS snowfall used in the a priori database. PMW TBs are highly sensitive to the ice particle shape and particle number distribution, which are temperature dependent.

Results showed that consistency between the snow products is achieved for some regions, but for the wrong reasons (Fig. 3). Consistency in eastern Europe, for example, is driven by underestimation of AMSR-E SWE, as well as snowfall. Perhaps the clearest conclusion of this study is that neither snowfall nor SWE is sufficiently consistent with each other or with other products to be globally useful at this time.

The snowfall and SWE communities have operated independently of each other despite the physical link between the two variables. A coupled snow algorithm for spaceborne PMW instruments would allow for synergistic improvements to the snow consistency problem. However, it is important to constrain the SWE estimates through initial snowfall estimates, which are shown to be significantly underestimated. Therefore, improving the snowfall accumulations is an important first step to improving snow consistency using PMW instruments.

Acknowledgments. The work was supported by NASA 80NSSC19K0140. Ryan Gonzalez was supported by the above funding. The authors thank Dr. Glen Liston for his snow science expertise and providing the SnowModel routines as well as three anonymous reviewers that provided useful suggestions to improve the manuscript.

Data availability statement. AMSR-E snow water equivalent and CMC data are obtained from the National Snow and Ice Data Center (https://doi.org/10.5067/AMSR-E/AE_DYSNO.002; https://doi.org/10.7265/N5TB14TC; https://doi.org/10.5067/ W9FOYWH0EQZ3). AMSR-E snowfall data is obtained from NASA's Precipitation Processing System database (https:// storm.pps.eosdis.nasa.gov/storm/). MERRA-2 reanalysis data are obtained from NASA's Global Modeling and Assimilation Office 
(https://gmao.gsfc.nasa.gov/reanalysis/MERRA-2/data_ access/). Snow climate classification data is provided by Glen Liston (personal communication).

\section{REFERENCES}

Auer, A. H., 1974: The rain versus snow threshold temperature. Weatherwise, 27, 67, http://doi.org/10.1080/00431672.1974.9931684.

Balk, B., and K. Elder, 2000: Combining binary decision tree and geostatistical methods to estimate snow distribution in a mountain watershed. Water Resour. Res., 36, 13-26, https:// doi.org/10.1029/1999WR900251.

Barnett, T. P., J. C. Adam, and D. P. Lettenmaier, 2005: Potential impacts of a warming climate on water availability in snowdominated regions. Nature, 438, 303-309, https://doi.org/10.1038/ nature04141.

Bosilovich, M. G., J. Chen, F. R. Robertson, and R. F. Adler, 2008: Evaluation of global precipitation in reanalyses. J. Appl. Meteor. Climatol., 47, 2279-2299, https://doi.org/ 10.1175/2008JAMC1921.1.

Brasnett, B., 1999: A global analysis of snow depth for numerical weather prediction. J. Appl. Meteor., 38, 726-740, https://doi.org/ 10.1175/1520-0450(1999)038<0726:AGAOSD > 2.0.CO;2.

Brown, R. D., and P. W. Mote, 2009: The response of Northern Hemisphere snow cover to a changing climate. J. Climate, 22, 2124-2145, https://doi.org/10.1175/2008JCLI2665.1.

Broxton, P. D., X. Zeng, and N. Dawson, 2016: Why do global reanalyses and land data assimilation products underestimate snow water equivalent? J. Hydrometeor., 17, 2743-2761, https://doi.org/10.1175/JHM-D-16-0056.1.

Cao, Q., T. H. Painter, W. R. Currier, J. D. Lundquist, and D. P. Lettenmaier, 2018: Estimation of precipitation over the OLYMPEX domain during winter 2015/16. J. Hydrometeor., 19, 143-160, https://doi.org/10.1175/JHM-D-17-0076.1.

Chang, A. T. C., J. L. Foster, and D. K. Hall, 1987: Nimbus-7 SMMR derived global snow cover parameters. Ann. Glaciol., 9, 39-44, https://doi.org/10.1017/S0260305500200736.

Clifford, D., 2010: Global estimates of snow water equivalent from passive microwave instruments: History, challenges and future developments. Int. J. Remote Sens., 31, 3707-3726, https:// doi.org/10.1080/01431161.2010.483482.

Conrick, R., and C. F. Mass, 2019: An evaluation of simulated precipitation characteristics during OLYMPEX. J. Hydrometeor., 20, 1147-1164, https://doi.org/10.1175/JHM-D-18-0144.1.

Cordisco, E., C. Prigent, and F. Aires, 2006: Snow characterization at a global scale with passive microwave satellite observations. J. Geophys. Res., 111, D19102, https://doi.org/ 10.1029/2005JD006773.

Cui, X., X. Guo, Y. Wang, X. Wang, W. Zhu, J. Shie, C. Lin, and X. Gao, 2019: Application of remote sensing to water environmental processes under a changing climate. J. Hydrol., 574, 892-902, https://doi.org/10.1016/j.jhydrol.2019.04.078.

Daly, C., R. Neilson, and D. Phillips, 1994: A statistical-topographic model for mapping climatological precipitation over mountainous terrain. J. Appl. Meteor., 33, 140-158, https://doi.org/ 10.1175/1520-0450(1994)033<0140:ASTMFM > 2.0.CO;2.

Dawson, N., P. Broxton, X. Zeng, M. Leuthold, M. Barlage, and P. Holbrook, 2016: An evaluation of snow initializations in NCEP global and regional forecasting models. J. Hydrometeor., 17, 1885-1901, https://doi.org/10.1175/ JHM-D-15-0227.1.

,$- \ldots$, and — 2018: Evaluation of remotely sensed snow water equivalent and snow cover extent over the contiguous
United States. J. Hydrometeor., 19, 1777-1791, https://doi.org/ 10.1175/JHM-D-18-0007.1.

Derksen, C., and M. MacKay, 2006: The Canadian boreal snow water equivalent band. Atmos.-Ocean, 44, 305-320, https:// doi.org/10.3137/ao.440307.

—, P. Toose, A. Rees, L. Wang, M. English, A. Walker, and M. Sturm, 2010: Development of a tundra-specific snow water equivalent retrieval algorithm for satellite passive microwave data. Remote Sens. Environ., 114, 1699-1709, https://doi.org/ 10.1016/j.rse.2010.02.019.

Ebtehaj, A. M., and C. D. Kummerow, 2017: Microwave retrievals of terrestrial precipitation over snow-covered surfaces: A lesson from the GPM satellite. Geophys. Res. Lett., 44, 61546162, https://doi.org/10.1002/2017GL073451.

Fassnacht, S. R., K. A. Dressler, and R. C. Bales, 2003: Snow water equivalent interpolation for the Colorado River Basin from Snow Telemetry (SNOTEL) data. Water Resour. Res., 39, 1208, https://doi.org/10.1029/2002WR001512.

Foster, J. L., A. T. C. Chang, and D. K. Hall, 1997: Comparison of snow mass estimates from a prototype passive microwave snow algorithm, a revised algorithm and a snow depth climatology. Remote Sens. Environ., 62, 132-142, https://doi.org/ 10.1016/S0034-4257(97)00085-0.

— C. Sun, J. P. Walker, R. Kelly, A. Chang, J. Dong, and H. Powell, 2005: Quantifying the uncertainty in passive microwave snow water equivalent observations. Remote Sens. Environ., 94, 187-203, https://doi.org/10.1016/j.rse.2004.09.012.

Gelaro, R., and Coauthors, 2017: The Modern-Era Retrospective Analysis for Research and Applications, version 2 (MERRA-2). J. Climate, 30, 5419-5454, https://doi.org/10.1175/JCLI-D16-0758.1.

Hancock, S., B. Huntley, R. Ellis, and R. Baxter, 2014: Biases in reanalysis snowfall found by comparing the JULES land surface model to GlobSnow. J. Climate, 27, 624-632, https:// doi.org/10.1175/JCLI-D-13-00382.1.

Hedrick, A. R., and Coauthors, 2018: Direct insertion of NASA airborne snow observatory-derived snow depth time series into the iSnobal energy balance snow model. Water Resour. Res., 54, 8045-8063, https://doi.org/10.1029/2018WR023190.

Heymsfield, A. J., C. Schmitt, and A. Bansemer, 2013: Ice cloud particle size distributions and pressure-dependent terminal velocities from in situ observations at temperatures from $0^{\circ}$ to $-86^{\circ}$ C. J. Atmos. Sci., 70, 4123-4154, https://doi.org/ 10.1175/JAS-D-12-0124.1.

—, M. Krämer, N. B. Wood, A. Gettelman, P. R. Field, and G. Liu, 2017: Dependence of the ice water content and snowfall rate on temperature, globally: Comparison of in situ observations, satellite active remote sensing retrievals, and global climate model simulations. J. Appl. Meteor. Climatol., 56, 189-215, https://doi.org/10.1175/JAMC-D-16-0230.1.

Hiemstra, C. A., G. E. Liston, and W. A. Reiners, 2002: Snow redistribution by wind and interactions with vegetation at upper treeline in the Medicine Bow Mountains, Wyoming, U.S.A. Arct. Antarct. Alp. Res., 34, 262-273, https://doi.org/10.1080/ 15230430.2002.12003493.

Hughes, M., J. D. Lundquist, and B. Henn, 2020: Dynamical downscaling improves upon gridded precipitation products in the Sierra Nevada, California. Climate Dyn., 55, 111-129, https://doi.org/10.1007/S00382-017-3631-Z.

Johnson, B. T., and G. Petty, 2001: The sensitivity of computed microwave brightness temperatures from precipitating clouds to models of spherical. 11th Conf. on Satellite Meteorology and Oceanography, Madison, WI, Amer. Meteor. Soc., 
P4.18, https://ams.confex.com/ams/11satellite/techprogram/ paper_24306.htm.

— , G. W. Petty, and G. Skofronick-Jackson, 2012: Microwave properties of ice-phase hydrometeors for radar and radiometers: Sensitivity to model assumptions. J. Appl. Meteor. Climatol., 51, 2152-2171, https://doi.org/10.1175/JAMC-D-11-0138.1.

Josberger, E. G., and N. M. Mognard, 2002: A passive microwave snow depth algorithm with a proxy for snow metamorphism. Hydrol. Processes, 16, 1557-1568, https://doi.org/10.1002/ hyp. 1020.

Kelly, R., 2009: The AMSR-E snow depth algorithm: Description and initial results. J. Remote Sens. Soc. Japan, 29, 307-317, https://doi.org/10.11440/rssj.29.307.

Kikuchi, K., and Coauthors, 2013: A global classification of snow crystals, ice crystals, and solid precipitation based on observations from middle latitudes to polar regions. Atmos. Res., 132133, 460-472, https://doi.org/10.1016/j.atmosres.2013.06.006.

Kim, M.-J., 2006: Single scattering parameters of randomly oriented snow particles at microwave frequencies. J. Geophys. Res., 111, D14201, https://doi.org/10.1029/2005JD006892.

Kulie, M. S., R. Bennartz, T. J. Greenwald, Y. Chen, and F. Weng, 2010: Uncertainties in microwave properties of frozen precipitation: Implications for remote sensing and data assimilation. J. Atmos. Sci., 67, 3471-3487, https://doi.org/10.1175/ 2010JAS3520.1.

Kummerow, C., 1993: On the accuracy of the Eddington approximation for radiative transfer in the microwave frequencies. J. Geophys. Res., 98, 2757-2765, https://doi.org/ 10.1029/92JD02472.

— W. W. Olson, and L. Giglio, 1996: A simplified scheme for obtaining precipitation and vertical hydrometeor profiles from passive microwave sensors. IEEE Trans. Geosci. Remote Sens., 34, 1213-1232, https://doi.org/10.1109/36.536538.

Kunkel, K. E., D. A. Robinson, S. Champion, X. Yin, T. Estilow, and R. M. Frankson, 2016: Trends and extremes in Northern Hemisphere snow characteristics. Curr. Climate Change Rep., 2, 65-73, https://doi.org/10.1007/s40641-016-0036-8.

Lee, Y.-K., C. Kongoli, and J. Key, 2015: An in-depth evaluation of heritage algorithms for snow cover and snow depth using AMSR-E and AMSR2 measurements. J. Atmos. Oceanic Technol., 32, 2319-2336, https://doi.org/10.1175/JTECH-D15-0100.1.

Levizzani, V., and E. Cattani, 2019: Satellite remote sensing of precipitation and the terrestrial water cycle in a changing climate. Remote Sens., 11, 2301, https://doi.org/10.3390/rs11192301.

_- S. Laviola, and E. Cattani, 2011: Detection and measurement of snowfall from space. Remote Sens., 3, 145-166, https:// doi.org/10.3390/rs3010145.

Liston, G. E., and M. Sturm, 1998: A snow-transport model for complex terrain. J. Glaciol., 44, 498-516, https://doi.org/ 10.1017/S0022143000002021.

- and - 2004: The role of winter sublimation in the Arctic moisture budget. Hydrol. Res., 35, 325-334, https://doi.org/ 10.2166/nh.2004.0024.

—_, and J.-G. Winther, 2005: Antarctic surface and subsurface snow and ice melt fluxes. J. Climate, 18, 1469-1481, https:// doi.org/10.1175/JCLI3344.1.

_ _ and K. Elder, 2006: A distributed snow-evolution modeling system (SnowModel). J. Hydrometeor., 7, 1259-1276, https:// doi.org/10.1175/JHM548.1.

- and C. A. Hiemstra, 2011: The changing cryosphere: PanArctic snow trends (1979-2009). J. Climate, 24, 5691-5712, https://doi.org/10.1175/JCLI-D-11-00081.1.
_ J.-G. Winther, O. S. Bruland, H. Elvehøy, and K. Sand, 1999: Below-surface ice melt on the coastal Antarctic ice sheet. J. Glaciol, 45, 273-285, https://doi.org/10.3189/S0022143000001775.

Liu, G., 2008: A database of microwave single-scattering properties for nonspherical ice particles. Bull. Amer. Meteor. Soc., 89, 1563-1570, https://doi.org/10.1175/2008BAMS2486.1.

_ high-frequency microwave observations: The lack of scattering signature and a statistical approach. J. Geophys. Res. Atmos., 118, 1376-1387, https://doi.org/10.1002/JGRD.50172.

López-Moreno, J. I., and D. Nogués-Bravo, 2006: Interpolating local snow depth data: an evaluation of methods. Hydrol. Processes, 20, 2217-2232, https://doi.org/10.1002/hyp.6199.

Lundquist, J. D., M. Hughes, B. Henn, E. D. Gutmann, B. Livneh, J. Dozier, and P. Neiman, 2015: High-elevation precipitation patterns: Using snow measurements to assess daily gridded datasets across the Sierra Nevada, California. J. Hydrometeor., 16, 1773-1792, https://doi.org/10.1175/JHM-D-15-0019.1.

Magono, C., and C. W. Lee, 1966: Meteorological classification of natural snow crystals. J. Fac. Sci., Hokkaido Univ., Ser. 7, 2 , 321-335.

Molotch, N. P., M. T. Colee, R. C. Bales, and J. Dozier, 2005: Estimating the spatial distribution of snow water equivalent in an alpine basin using binary regression tree models: the impact of digital elevation data and independent variable selection. Hydrol. Processes, 19, 1459-1479, https://doi.org/ 10.1002/hyp.5586.

Mote, P. W., A. F. Hamlet, M. P. Clark, and D. P. Lettenmaier, 2005: Declining mountain snowpack in western North America. Bull. Amer. Meteor. Soc., 86, 39-50, https:// doi.org/10.1175/BAMS-86-1-39.

Mudryk, L. R., C. Derksen, P. J. Kushner, and R. Brown, 2015: Characterization of Northern Hemisphere snow water equivalent datasets, 1981-2010. J. Climate, 28, 8037-8051, https:// doi.org/10.1175/JCLI-D-15-0229.1.

Nakaya, U., 1951: The formation of ice crystals. Compendium of Meteorology, T.F. Malone, Ed., Amer. Meteor. Soc., 207-220.

Passive Microwave Algorithm Team, 2017: Global Precipitation Measurement (GPM) Mission ATBD. NASA Tech Rep., 64 pp., https://rain.atmos.colostate.edu/ATBD/ATBD_GPM_ October1_2017.pdf.

Pederson, G. T., S. T. Gray, T. Ault, W. Marsh, D. B. Fagre, A. G. Bunn, C. A. Woodhouse, and L. J. Graumlich, 2011: Climatic controls on the snowmelt hydrology of the northern rocky mountains. J. Climate, 24, 1666-1687, https://doi.org/10.1175/ 2010JCLI3729.1.

Raleigh, M. S., B. Livneh, K. Lapo, and J. D. Lundquist, 2016: How does availability of meteorological forcing data impact physically based snowpack simulations? J. Hydrometeor., 17, 99120, https://doi.org/10.1175/JHM-D-14-0235.1.

Rasmussen, R., and Coauthors, 2012: How well are we measuring snow: The NOAA/FAA/NCAR winter precipitation test bed. Bull. Amer. Meteor. Soc., 93, 811-829, https://doi.org/10.1175/ BAMS-D-11-00052.1.

Reichle, R. H., C. S. Draper, Q. Liu, M. Girotto, S. P. P. Mahanama, R. D. Koster, and G. J. M. De Lannoy, 2017: Assessment of MERRA-2 land surface hydrology estimates. J. Climate, 30, 2937-2960, https://doi.org/10.1175/JCLI-D-16-0720.1.

Robinson, A., and A. Frei, 2000: Seasonal variability of Northern Hemisphere snow extent using variable satellite data. Prof. Geog., 52, 307-315, https://doi.org/doi:10.1111/0033-0124.00226.

Shige, S., S. Kida, H. Ashiwake, T. Kubota, and K. Aonashi, 2013: Improvement of TMI rain retrievals in mountainous 
areas. J. Appl. Meteor. Climatol., 52, 242-254, https:// doi.org/10.1175/JAMC-D-12-074.1.

Sturm, M., J. Holmgren, and G. E. Liston, 1995: A seasonal snow cover classification system for local to global applications. J. Climate, 8, 1261-1283, https://doi.org/10.1175/ 1520-0442(1995)008<1261:ASSCCS>2.0.CO;2.

— B. Baras, G. E. Liston, C. Derksen, T. Jonas, and J. Lea, 2010: Estimating snow water equivalent using snow depth data and climate classes. J. Hydrometeor., 11, 1380-1394, https://doi.org/10.1175/2010JHM1202.1.

Syed, T. H., J. S. Famiglietti, M. Rodell, J. Chen, and C. R. Wilson, 2008: Analysis of terrestrial water storage changes from Grace and GLDAS. Water Resour. Res., 44, W02433, https://doi.org/ 10.1029/2006WR005779.

Takbiri, Z., A. Ebtehaj, E. Foufoula-Georgiou, P.-E. Kirstetter, and F. J. Turk, 2019: A prognostic nested $k$-nearest approach for microwave precipitation phase detection over snow cover. J. Hydrometeor., 20, 251-274, https://doi.org/10.1175/JHM-D18-0021.1.

Tedesco, M., and P. S. Narvekar, 2010: Assessment of the NASA AMSR-E SWE product. IEEE J. Sel. Top. Appl. Earth Obs. Remote Sens., 3, 141-159, https://doi.org/ 10.1109/JSTARS.2010.2040462.

_ _ and J. Jeyaratnam, 2016: A new operational snow retrieval algorithm applied to historical AMSR-E brightness temperatures. Remote Sens., 8, 1037, https://doi.org/10.3390/rs8121037.

Toure, A. M., M. Rodell, Z.-L. Yang, H. Beaudoing, E. Kim, Y. Zhang, and Y. Kwon, 2016: Evaluation of the snow simulations from the Community Land Model, version 4 (CLM4). J. Hydrometeor., 17, 153-170, https://doi.org/10.1175/JHM-D14-0165.1.

Ulaby, F. T., and W. H. Stiles, 1980: The active and passive microwave response to snow parameters: 2 . Water equivalent of dry snow. J. Geophys. Res., 85, 1045, https://doi.org/10.1029/ JC085iC02p01045.

Vuyovich, C. M., J. M. Jacobs, and S. F. Daly, 2014: Comparison of passive microwave and modeled estimates of total watershed SWE in the continental United States. Water Resour. Res., 50, 9088-9102, https://doi.org/10.1002/2013WR014734.

Wen, Y., P. Kirstetter, J. J. Gourley, Y. Hong, A. Behrangi, and Z. Flamig, 2017: Evaluation of MRMS snowfall products over the Western United States. J. Hydrometeor., 18, 1707-1713, https://doi.org/10.1175/JHM-D-16-0266.1.

Wrzesien, M. L., M. T. Durand, T. M. Pavelsky, I. M. Howat, S. A. Margulis, and L. S. Huning, 2017: Comparison of methods to estimate snow water equivalent at the mountain range scale: A case study of the California Sierra Nevada. J. Hydrometeor., 18, 1101-1119, https://doi.org/10.1175/ JHM-D-16-0246.1.

,,--- , S. B. Kapnick, Y. Zhang, J. Guo, and C. K. Shum, 2018: A new estimate of North American mountain snow accumulation from regional climate model simulations. Geophys. Res. Lett., 45, 1423-1432, https://doi.org/10.1002/ 2017GL076664.

— T. M. Pavelsky, M. T. Durand, J. Dozier, and J. D. Lundquist, 2019: Characterizing biases in mountain snow accumulation from global data sets. Water Resour. Res., 55, 9873-9891, https://doi.org/10.1029/2019WR025350.

Yang, P., L. Bi, B. A. Baum, K.-N. Liou, G. W. Kattawar, M. I. Mishchenko, and B. Cole, 2013: Spectrally consistent scattering, absorption, and polarization properties of atmospheric ice crystals at wavelengths from 0.2 to $100 \mu \mathrm{m}$. J. Atmos. Sci., 70, 330-347, https://doi.org/10.1175/JAS-D-12-039.1.

Zeng, X., P. Broxton, and N. Dawson, 2018: Snowpack change from 1982 to 2016 over the conterminous United States. Geophys. Res. Lett., 45, 12 940-12 947, https://doi.org/10.1029/2018GL079621. 